\title{
DOMOS VOLCÁNICOS Y MINERALIZACIÓN DE ORO EN EL DISTRITO PUEBLO VIEJO, REPÚBLICA DOMINICANA
}

\author{
Carl E. Nelson ${ }^{1)}$, Jorge Jiménez ${ }^{2)}$ \& Juan José Rodríguez ${ }^{3)}$ \\ 1) 2360 23rd Street Boulder, Colorado 80304, E-mail: nelson@ cbmap.net \\ 2) Falconbridge Dominicana S.A. Apartado Postal 1343; Avenida Máximo Gomez, 30 \\ Santo Domingo, República Dominicana \\ 3) Rosario Dominicana S.A. Apartado Postal 944; Avenida 27 de Febrero, 220 \\ Santo Domingo, República Dominicana
}

(Recibido 15/5/01; Aceptado 3/7/01)

\begin{abstract}
Gold mineralization in the Pueblo Viejo district, Dominican Republic is spatially and temporally related to a series of Early Cretaceous volcanic domes. Separate but overlapping hydrothermal cells, centered on the domes, together deposited more than 40 million ounces of gold, 240 million ounces of silver, 3 million tonnes of zinc, and 0.4 million tonnes of copper. Two principal deposits (Moore and Monte Negro) and a number of smaller deposits (Cumba, Mejita, Upper Mejita, Banco V, Arroyo Hondo I and II) have contributed ore since mining commenced in 1975.

Geologic mapping in the Pueblo Viejo District has identified a series of at least seven volcanic centers that interfinger, overlap, and are interbedded with locally derived epiclastic sediments. These volcanic centers are centered on previously-unrecognized volcanic domes that vary from andesite to dacite in composition. Epiclastic volcanic sediments surround the domes and reflect the composition of the local source rock. A dacite porphyry dome in the Moore deposit is surrounded by epiclastic sediments that contain detrital quartz eyes and debris flows of dacite porphyry. Andesite domes in the Monte Negro, Cumba and Mejita deposits are surrounded by epiclastic crumble breccias and volcaniclastic sediments.

Field relations indicate that volcanic dome emplacement, epiclastic sediment accumulation, hydrothermal alteration, and gold mineralization were coeval events. Domes were emplaced in a shallow subaqueous environment on the flanks of an emergent volcanic edifice. Hydrothermal cells responsible for gold mineralization are controlled by high-angle faults. These same faults influenced the emplacement of volcanic domes, an essential step in the development of gold ore in the Pueblo Viejo district.
\end{abstract}

RESUMEN: La mineralización de oro en el Distrito PuebloViejo de la República Dominicana se encuentra relacionada espacial y temporalmente con una serie de domos volcánicos del Cretácico Inferior. Las celdas hidrotermales separadas, pero solapadas, centradas en los domos, depositaron en conjunto más de 40 millones de onzas de oro, 240 millones de onzas de plata, 3 millones de toneladas métricas de cinc y 0,4 millones de toneladas métricas de cobre. Los dos depósitos principales (Moore y Monte Negro) y varios depósitos más pequeños (Cumba, Mejita, Mejita Arriba, Banco 5, Arroyo Hondo I y II) han producido mena desde que comenzó la mina en 1975.

Cartografía geológica del Distrito Pueblo Viejo ha identificado por lo menos siete centros volcanicos los cuales se interdigitan, solapan y se encuentran interestratificados con sedimentos epiclásticos derivados localmente. Éstos 


\begin{abstract}
centros se localizan sobre domos volcánicos que varían en composición entre andesita y dacita. Los sedimentos volcánicos epiclásticos que rodean cada domo reflejan la composición de la roca fuente local. Un domo dacítico en el depósito de Moore se encuentra rodeado de sedimentos epiclásticos con ojos de cuarzo detrítico y restos de flujo de pórfido dacítico. Domos andesíticos en los depósitos de Monte Negro, Cumba, y Mejita se encuentran rodeado y parcialmente cubiertos por brechas de origen mixto, epiclástica y piroclástica, y por sedimentos volcánicos andesíticos.

Las relaciones de campo indican que el emplazamiento de domos volcánicos, la acumulación de sedimentos epiclásticos, la alteración hidrotermal y la mineralización de oro fueron eventos contemporáneos. Los domos fueron emplazados en un ambiente subacuático de poca profundidad en los flancos de un emergente edificio volcánico. Las celdas hidrotermales responsables de la mineralización del oro están controladas por fallas de ángulo empinado. Estas mismas fallas influenciaron en el emplazamiento de los domos, los cuales son considerados como una etapa esencial en el desarrollo de la mena de oro del Distrito de Pueblo Viejo.
\end{abstract}

\section{INTRODUCCIÓN}

Los depósitos de oro del Distrito de Pueblo Viejo representan uno de los recursos de oro y plata más grandes del mundo, por lo que son de interés especial para los geólogos de exploración.
Este artículo presenta los resultados de la cartografía geológica detallada del distrito, llevada a cabo por el primer autor durante los años 1996 y 1997. El mapa está enfocado en una serie de domos volcánicos no reconocidos previamente, los cuales se encuentran relacionados temporal y

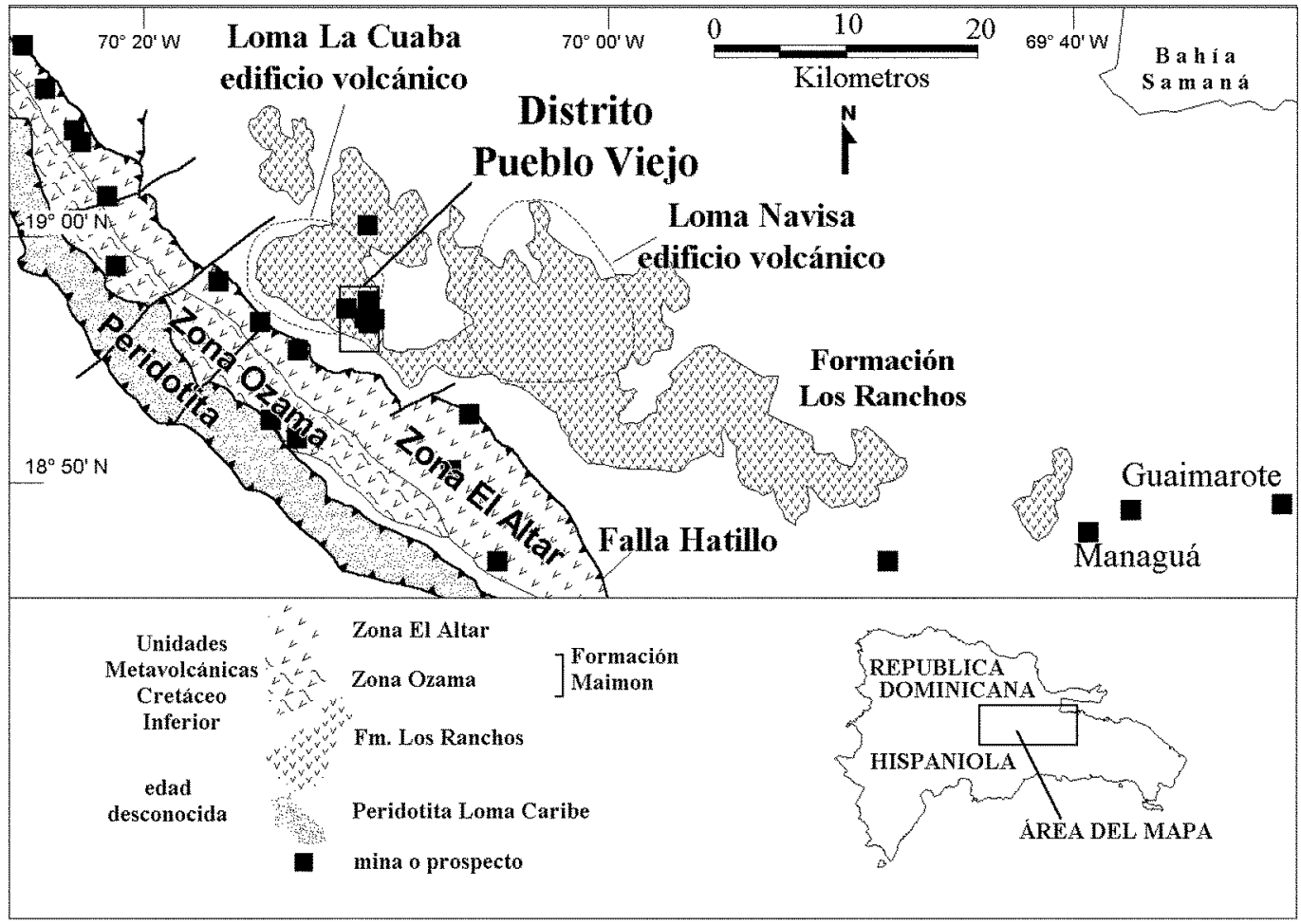

Fig. 1: Mapa de ubicación del Distrito de Pueblo Viejo mostrando rocas del Cretácico Temprano y los prospectos cercanos de metales base y de metales preciosos. Las áreas mostradas en blanco están ocupadas por rocas más jóvenes y cubierta aluvional. La distribución de la Formación Los Ranchos es tomada de Mann et al. (1991). La zona de cizallamiento del Ozama, la zona de El Altar y las fallas de cabalgamiento limítrofes están tomadas de Draper et al. (1996). El contacto de falla de cabalgamiento de la peridotita es de Toloczyki \& Ramírez (1991). 
espacialmente con la alteración hidrotermal y con la mineralización de metales preciosos. En la figura 1 se presenta el mapa de localización del Distrito de Pueblo Viejo y la de los prospectos circundantes de metales base y preciosos.

Una serie de importantes artículos han tratado sobre la geología del Distrito Pueblo Viejo. Kesler et al. (1981) describieron un ambiente restringido de hoya submarina en el flanco de un volcán, similar al formado cerca del volcán Momotombo en la margen del actual Lago Managua en Nicaragua. Sillitoe \& Bonham (1984) sugirieron que la porción de la sección sedimentaria fue de origen piroclástico y propusieron un marco de maar-diatrema. Bajo esta interpretación la hoya restringida descrita por Kesler et al. (1981) rellena un cráter maar y su diatrema. Russell \& Kesler (1991) aceptaron el maar-diatrema como marco geológico en Pueblo Viejo pero sugirieron que la erosión removió el abanico piroclástico. La distinción entre unidades piroclásticas, epiclásticas, un tópico de controversia de mucho tiempo en Pueblo Viejo, se describe en detalle en la parte descriptiva de este artículo. Muchas unidades rocosas son reinterpetadas basado en las relaciones de campo observadas durante la cartografía geológica.

\section{GEOLOGÍA REGIONAL}

La roca caja de las menas del Distrito de Pueblo Viejo pertenece a la Formación Los Ranchos del Cretácico Inferior (Fig. 1), parte de uno de los arcos de islas químicamente más primitivos del basamento del Caribe. Donnelly \& Rogers (1981) usaron el término primitivo para describir la Formación Los Ranchos y rocas volcánicas similares: 1) que se formaron en la etapa de evolución temprana del arco de islas; 2) las cuales no fueron derivadas por diferenciación de algún tipo de magma; y 3) en la cual los elementos de iones litófilos grandes no fueron enriquecidos durante la diferenciación.

Los autores anteriores, comenzando por Bowin (1966), describieron las rocas volcánicas de la Formación Los Ranchos como espilitas y queratófiros. Cas \& Wright (1995), sin embargo, recomendaron que, aunque sea para rocas volcánicas alteradas, se siguiera, cuando fuera posible, el esquema de clasificación Streckeisen (1979). En consecuencia, los términos espilita y queratófiro serán aquí abandonados. En su lugar, las rocas volcánicas de la Formación Los Ranchos serán referidas como andesitas y dacitas, basado en su ensamblaje fenocristalino y en la geoquímica de elementos mayores de veintiséis muestras colectadas por Kesler et al. (1991). Kesler et al. (1991) reportaron una distribución bimodal de sílice para las rocas volcánicas de la Formación Los Ranchos, andesita basáltica y dacita. Díaz de Villavilla et al. (1997) reportan una química bimodal para rocas similares del Cretácico Inferior en Cuba.

Las rocas volcánicas del Distrito Pueblo Viejo fueron espilitizadas al interactuar con agua marina, fueron alteradas hidrotermalmente durante el emplazamiento de los domos volcánicos y, despues, fueron metamorfisadas regionalmente. El examen de láminas delgadas revela un reemplazamiento secundario de los fenocristales y la matriz. Sin embargo, a menudo se pueden identificar las fases fenocristalinas primarias. El uso del término andesita para rocas descritas previamente como espilita es apropiado, dado el ensamblaje común de fenocristales de plagioclasa y clinopiroxeno. Algunas muestras contienen una fase fenocristalina alterada que probablemente fue olivino, clinopiroxeno u ortopiroxeno (Kesler et al., 1991) y algunas muestras de domos volcánicos contienen fenocristales de cuarzo, feldespato potásico y biotita (Honea, com. escrita 1997). La composición original de la Formación Los Ranchos en el Distrito de Pueblo Viejo varió probablemente de basalto a andesita basáltica, andesita y dacita.

Mann et al. (1991) hicieron un estudio regional sobre la geología y la evolución tectónica de la isla de La Española. El fragmento de corteza oceánica (peridotita) mostrado entre fallas de cabalgamiento en la figura 1 , ha sido interpretado como una zona de subducción anterior (Bowin, 1975) y como una ofiolita (Draper \& Lewis, 1989). Una publicación de Draper et al. (1996) introdujo las llamadas zonas de cizallamiento de El Altar y del Ozama (Fig. 1) paras rocas asignadas previamente a la Formación Maimón del Cretácico Inferior. Bajo esta interpretación la obducción del piso oceánico durante el Aptiense-Albiense Inferior fue la responsable del cizallamiento y del 
metamorfismo de las rocas volcánicas y sedimentarias de la Formación Maimón. La Formación Los Ranchos fue afectada de manera similar cerca de la falla de cabalgamiento de Hatillo. Las rocas sedimentarias carbonosas de la Formación Los Ranchos en el Distrito Pueblo Viejo exhiben clivaje de plano axial y recristalización metamórfica.

\section{HISTORIA MINERA}

La producción de oro de la mina de Pueblo Viejo ha sido en promedio de unas 200000 onzas anuales desde que comenzó la operación a cielo abierto en el 1975. Durante los años 1976 y 1981 se alcanzaron picos de más de 410000 onzas. Sin embargo, a medida que la reserva de óxido se agotaba gradualmente, tanto el tonelaje como la proporción recuperada de oro caían a mediados de los años 1980. Pueblo Viejo cerró en 1993, reabrió en 1994, operó reducidamente por varios años y cerró otra vez en 1999. Ruiz (1997) reporta una producción total, hasta 1996, de 5335918 onzas de oro y 24422758 onzas de plata.

El cuadro 1, condensada de Ruiz (1997), ofrece un estimado del tamaño hipogénico del recurso de oro para diferentes leyes de corte. Aún a una ley relativamente alta, el recurso de los sulfuros es impresionante (9,36 millones de onzas a una ley de corte de 3,0 g/t Au). A una ley por encima de $1,0 \mathrm{~g} / \mathrm{t} \mathrm{Au}$, el recurso se aproxima a 35 millones de onzas (1000 toneladas métricas). Aunque sólo se ha recuperado oro y plata, también existen valores anómalos de metales base. El cinc que promedia $1,0 \%$ a una ley de corte de oro de 5,0 ppm (Ruiz, 1997), podría recuperarse mediante la adición de un circuito de flotación. El cobre promedia $0,2 \%$ a una ley de corte de oro de 2,5 ppm.

El oro de los sulfuros no ha respondido bien al circuito de lixiviación de carbón de la mina. En 1997, el promedio de recuperación de oro en Pueblo Viejo fue de aproximadamente $45 \%$. La ley de corte era de un gramo de oro recuperable, por tonelada métrica. La encapsulación por sulfuros (el contenido de sulfuros es de un $8 \%$ ), la competencia por carbón (el contenido de carbón es de 0,5\%), el alto contenido de arsénico (2000 ppm en promedio), la encapsulación de sílice (afecta aproximadamente el $10 \%$ del oro) y el alto contenido de cobre y cinc (lo cual aumenta el consumo de cianuro) tienen todo un efecto adverso en la recuperación del oro. Es difícil que se recupere la producción de oro hasta que se puedan hacer mejoramientos en la planta que permitan evaluar y mejorar los problemas metalúrgicos.

En el cuadro 2 se ofrece un resumen geoquímico de la mena de Pueblo Viejo. Todas las muestras de alteración recolectadas en los sulfuros contienen más de $1 \mathrm{ppm}$ de oro. Se incluyen algunas muestras de rocas caja no alteradas para la comparación. Los datos muestran que la mineralización de Pueblo Viejo está enriquecida en un conjunto de elementos epitermales que incluyen $\mathrm{Au}, \mathrm{Ag}, \mathrm{As}, \mathrm{Sb}$ y $\mathrm{Hg}$ así como $\mathrm{Cu}, \mathrm{Pb}, \mathrm{Zn}$ y Te.

Cuadro 1

Recursos de Sulfuros del Distrito de Pueblo Viejo*

\begin{tabular}{|c|c|c|c|c|}
\hline Tamaño del depósito & $\begin{array}{l}\text { Ley promedio } \\
\text { de oro } \\
(\mathrm{g} / \mathrm{t})\end{array}$ & $\begin{array}{l}\text { Ley promedia } \\
\text { de plata } \\
(\mathrm{g} / \mathrm{t})\end{array}$ & $\begin{array}{c}\text { Contenido oro } \\
\text { (millones toneladas) } \\
\text { (millones de onzas troy) }\end{array}$ & $\begin{array}{c}\text { Ley de corte }(\mathrm{g} / \mathrm{t}) \\
\text { en toneladas }\end{array}$ \\
\hline 544,34 & 1,98 & 11,76 & $1078(34,65)$ & 1,0 \\
\hline 321,42 & 2,50 & 14,47 & $804(25,83)$ & 1,5 \\
\hline 188,92 & 3,06 & 17,63 & $578(18,59)$ & 2,0 \\
\hline 69,81 & 4,17 & 25,13 & $291(9,36)$ & 3,0 \\
\hline 28,30 & 5,29 & 33,98 & $150(4,81)$ & 4,0 \\
\hline 12,99 & 6,31 & 41,94 & $82(2,63)$ & 5,0 \\
\hline
\end{tabular}


NELSON et al.: Domos volcánicos y mineralización de oro...

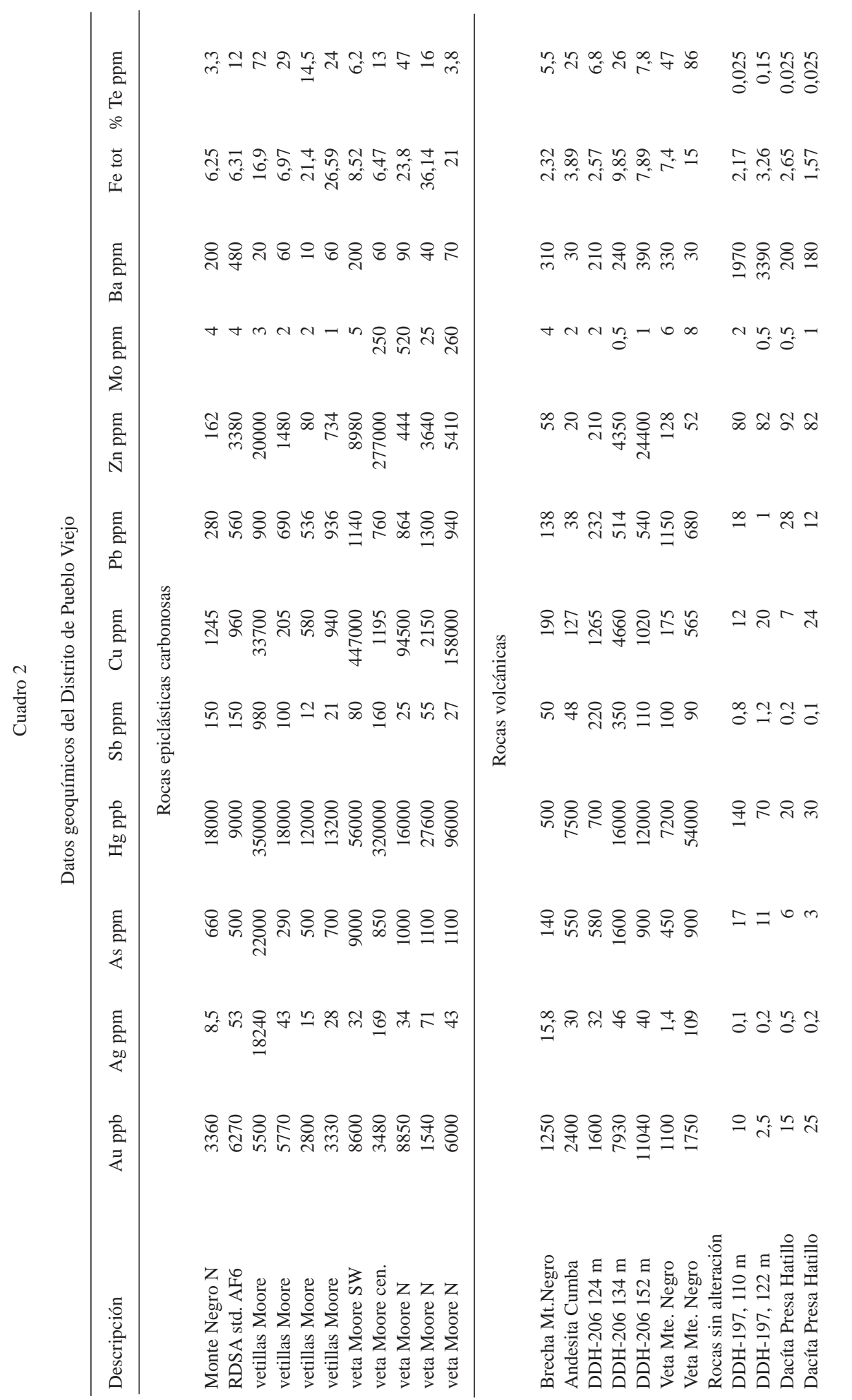




\section{MINERALIZACIÓN DE ORO}

Las estructuras mineralizadas con más frecuencia en el Distrito de Pueblo Viejo, son las de tensión con rumbo norte. Menos vetas siguen fallas normales con tendencias noroeste y noreste. Estas fallas de ángulo inclinado se encontraban activas mientras las rocas sedimentarias se acumulaban, como indica el aumento de los desplazamientos de las capas sedimentarias a lo largo de las fallas a profundidad. Vetas de cuarzo con sulfuros hidrotermales de alta ley llenan fallas alimentadoras empinadas y se encuentran rodeadas de una envoltura gruesa (de hasta $30 \mathrm{~m}$ de espesor) de minerales de sulfuro diseminado con oro. Estas envolturas se encuentran bien expuestas en los depósitos de Moore y de Monte Negro. Típicamente las vetas contienen cuarzo y pirita con cantidades variables de esfalerita, galena y enargita. El oro aparece como elemento nativo, electrum y minerales de teluro. Baritina y alunita aparecen localmente pero no son abundantes.

Una característica chocante de la alteración hidrotermal del Distrito Pueblo Viejo es la cantidad extraordinaria de azufre reducido (más de 40 millones de toneladas métricas). El azufre promedia un $8 \%$ en la mena de Pueblo Viejo y aumenta con la profundidad a un promedio de 10 $\%$. Algunas capas de rocas sedimentarias carbonosas epiclásticas contienen hasta 50 a $70 \%$ de pirita. No está todavia decidido si estos estratos de sulfuros masivos se formaron por acumulación de sedimentos sulfúricos o por reemplazamiento hidrotermal. La abundancia de pirita diseminada framboidal indica que por lo menos una parte de la pirita es de origen diagenético.

Los sulfuros están acompañados de cuarzo y pirofilita, un avanzado ensamblaje de alteración argilitica según Corbett \& Leach (1998). La temperatura de los fluidos hidrotermales excedió localmente $285^{\circ} \mathrm{C}$, según el equilibrio de los minerales pirofilita y diáspora (Muntean et al., 1990). Estas temperaturas se acercan a las determinadas por la geoquímica de isótopo de azufre (más de $250^{\circ} \mathrm{C}$ ) por Vennemann et al. (1993). Kesler et al. (1981) reportaron temperaturas de homogeneización de inclusiones fluidas de $135^{\circ}$ a $195^{\circ} \mathrm{C}$.
La silicificación afecta todas las unidades rocosas del Distrito de Pueblo Viejo y es más fuerte adyacente a fallas alimentadoras de ángulo empinado. Clastos silicificados son comunes en las secciones epiclásticas sedimentarias, dentro de domos volcánicos y las brechas fragmentarias que los cubren y en unidades de rocas volcánicas, tales como brechas volcaniclasticas y tobas de lapilli. Estas observaciones indican que el hidrovulcanismo, el emplazamiento de domos, la erosión, la acumulación sedimentaria, la alteración hidrotermal y la mineralización de oro fueron eventos coexistentes del Cretácico Temprano.

Varias publicaciones enfocan la alteración hidrotermal y la química de la precipitación de oro. Muntean et al. (1990) describieron dos etapas de alteración argilitica avanzada con oro, superimpuestas en rocas caja, que fueron alteradas regionalmente por su interacción con agua de mar. La etapa I se caracteriza por alunita + cuarzo + pirita y está cubierta por caolinita + cuarzo + pirita. $\mathrm{La}$ etapa II produjo pirofilita +/- diáspora y una capa de sílice que la cubre. La capa silícea es cortada por vetas de alta ley conteniendo pirita +/- esfalerita +/- enargita. Kettler et al. (1992) describieron yacimientos enriquecidos en azufre y propusieron un argumento para la precipitación de oro, como respuesta a la sulfuración del hierro contenido en la siderita diagenética.

Estudios de isótopos radiométricos estables han sido publicados por Kesler et al. (1981), Cumming et al. (1982), Kettler et al. (1992) y Vennemann et al. (1993). Kesler et al. (1981) concluyeron que el azufre fue derivado del agua del mar, que el carbón es de orígen orgánico y que el plomo y el estroncio vinieron de la Formación Los Ranchos. Ellos sugieren que los metales base y preciosos también se derivaron de la Formación Los Ranchos. Cumming et al. (1982) concluyeron que el plomo se derivó de la Formación Los Ranchos, igual que Kesler et al. (1981). Ellos sugirieron que los metales base y preciosos fueron lixiviados de ésta formación por circulación de fluidos hidrotermales. Kettler et al. (1992) argumentaron que el azufre de los sulfuros de Pueblo Viejo tiene un origen dual: La pirita framboidal se formó por reducción biogenética de sulfatos y la pirita diseminada no framboidal 
se formó por la sulfuración del hierro. Se propuso que las fuentes del azufre fueron fluidos magmáticos-hidrotermales. Vennemann et al. (1993) describieron dos etapas de alteración argilitica y concluyeron que el azufre de ambas etapas fue de origen magmático. Estas publicaciones reflejan una evolución gradual alejándose de la circulación de los fluidos hidrotermales y la lixiviación como fuente de metales, hacia una contribución directa de los fluidos magmáticos.

\section{GEOLOGÍA DEL DISTRITO PUEBLO VIEJO}

La cartografía geológica de los yacimientos de Pueblo Viejo (Moore, Monte Negro, Mejita, Mejita Arriba, Cumba, Arroyo Hondo I y II, y Banco 5) a escala 1:2000 fue realizado por el primer autor. Cada uno de estos depósitos está asociado con uno o más domos volcánicos, no reconocidos previamente, y rodeado por sedimentos
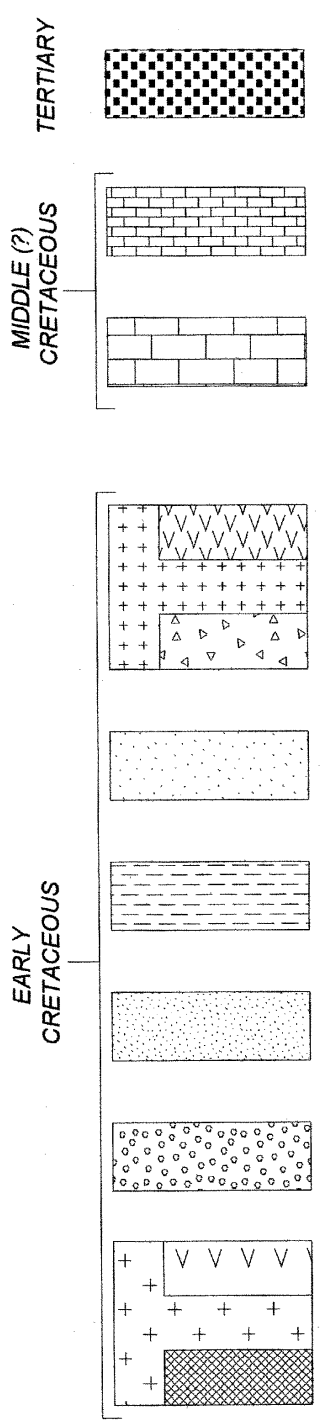

Intrusivos dioriticos de grano fino, sin alteración hidrotermal

\section{Formación Las Lagunas}

Limolitas calcáreas estratificada finamente y

filitas con capas de caliza interestratificadas.

\section{Hatillo Formation \\ Calizas masivas de arrecife}

\section{Formación Los Ranchos \\ Domo dacitico y falda piroclástica. Incluye: \\ - toba lapilli masiva con fragmentos liticos que llevan alteración hidrotermal y ojos de cuarzo (patrón v). \\ - domo dacitico masivo con ojos de cuarzos (patrón +). \\ - brecha dacítica con matriz (patrón de triángulos).}

Sedimentos epiclásticos arenosos estratificados $(5-50 \mathrm{~cm})$ con capas de limolita carbonácea. Conglomerados al lado de los domos.

Limolita epiclástica carbonosa finamente estratificada $(.5-5 \mathrm{~cm})$ con capas de arenisca carbonosa. Grano grueso al lado de los domos.

Brecha de toba lapili epiclástica con capas sedimentarias carbonosas. Cambia gradualmente con arenisca carbonosa.

Mantos de brecha fragmentaria desmoronada con clastos de andesita y, en menor cantidad, sedimentos epiclásticos.

Al lado de los domos andesiticos.

Flujos, domos y faldas piroclásticas andesiticas. Incluye:

- toba becha lapili masiva con abundantes clastos de composición máfico hasta intermedio y sin ojos de cuarzo (patrón V).

- domos y flujos de andesita masiva de textura porfiritica de abundantes feldespatos (patrón +).

diques andesiticos casi verticales (sombreado).

Fig. 2: Perfil estratigráfico del Distrito de Pueblo Viejo. Los patrones se refieren a las figuras 3, 4 y 6. 


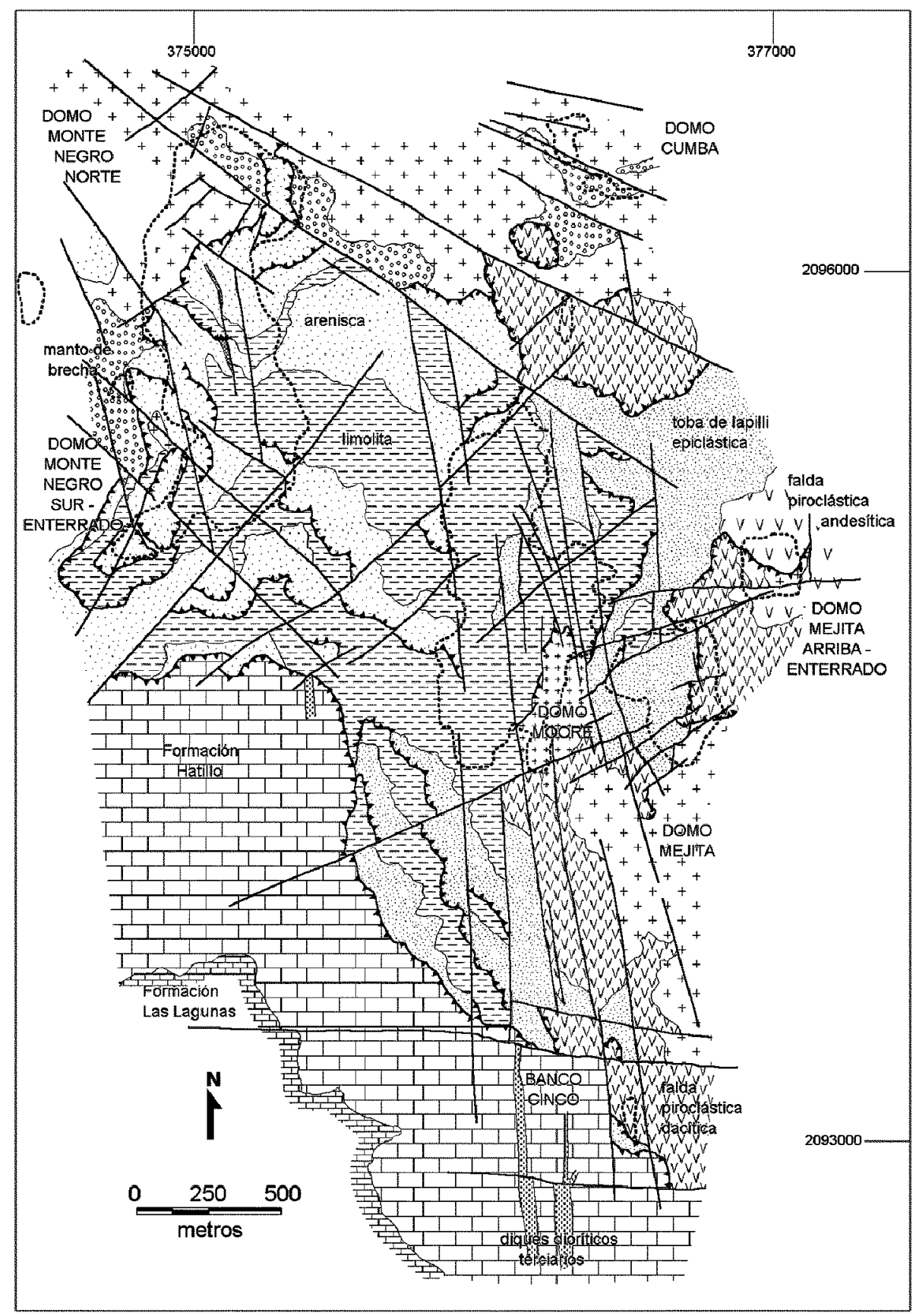

Fig. 3: Mapa geológico del Distrito de Pueblo Viejo mostrando la localización de los domos volcánicos dentro de la Formación Los Ranchos y el trazado de los tajos (líneas gruesas). Los símbolos de rumbo y buzamiento se han omitido para mayor claridad; las unidades sedimentarias son subhorizontales. Ver figura 4 para más detalles y una sección a través de los domos volcánicos en los yacimientos de Moore y Mejita. Ver la figura 6 para más detalles y una sección a través de los domos volcánicos en el yacimiento de Monte Negro. Ver figura 2 para una descripción de las unidades rocosas. 
vulcanoclásticos epiclásticos. La figura 2 presenta una sección estratigráfica junto a los símbolos de las unidades rocosas que se muestran en la figura 3. Esta versión, reducida de un mapa escala 1:5000 del Distrito Pueblo Viejo (Fig. 3), muestra la localización de los domos volcánicos junto al trazado del tajo, el cual sirve de referencia para localizar los yacimientos.

Los domos incluyen complejos de flujo /domo de andesita exógena en los yacimientos de Monte Negro, Mejita, Mejita Arriba y Cumba y un domo porfirítico volcánico intrusivo de dacita en el depósito de Moore. Cada uno de los domos se nombra con el mismo nombre del yacimiento al cual se asocia espacialmente. Los domos volcánicos y las rocas que les rodean se describen con más detalle más abajo.

Todos los domos forman parte de la Formación Los Ranchos del Cretácico Temprano. La Formación Los Ranchos fue dividida en cuatro miembros por Kesler et al. (1981) y posteriormente modificada a seis miembros por Kesler et al. (1991). Kesler et al. (1981, 1991) describen al miembro espilítico Platanal como la unidad volcánica máfica dominante en la zona de la mina. Consiste en un flujo amigdaloidal y aglomerádico y contiene fenocristales de clinopiroxeno y plagioclasa. Esta unidad es similar a la que aflora en Loma Navisa, la cual forma el próximo edificio volcánico hacia el este (Fig. 1). La espilita de Platanal se encuentra por encima del miembro fragmentario Meladito, el cual consiste en flujos basales, que a su vez se encuentran sobre areniscas volcánicas y tobas volcánicas. La espilita de Platanal está cubierta por los sedimentos del miembro Pueblo Viejo, una secuencia de areniscas y limolitas carbonosas estratificada finamente, que contiene plantas fósiles de edad Neocomiense (Kesler et al., 1991).

La estratigrafía descrita por Kesler et al. (1981, 1991) ha sido modificada durante la cartografía en el área de la mina. En vez de una serie de seis capas, la cartografía geológica describe una serie de centros volcánicos solapados, cada uno de los cuales exhibe una estratigrafía única. Al seguir esta interpretación las rocas fragmentarias gruesas asignadas previamente al Miembro Meladito, pueden aparecer dentro de las andesitas que fueron cartografiadas previamente como las espilitas de Platanal. Por su parte, las espilitas de Platanal se encuentran subyacidas y cubiertas por rocas sedimentarias carbonosas, cartografiadas previamente como el Miembro Pueblo Viejo. La sección estratigráfica para la Formación Los Ranchos es presentada en la figura 2. Sin embargo, esta sección no intenta implicar que la andesita se encuentra cubierta por sedimentos epiclásticos, que a su vez están cubiertos por pórfidos dacíticos. En cambio, una serie de siete centros volcánicos de composición dacítica y andesítica se entrelazan y solapan y se encuentran mezcladas con sedimentos epiclásticos derivados localmente.

La Formación Los Ranchos está cubierta por la Caliza de Hatillo, una caliza masiva del Cretácico Superior (Albiense a Cenomiense segun Kesler et al., 1991). El contacto basal de la Caliza de Hatillo en el área de la mina, descrito como una discontinuidad por Russell \& Kesler (1991), está comúnmente desplazado por fallas de cabalgamiento. La Caliza Hatillo está cubierta conformablemente por la Formación Las Lagunas, una limolita tobácea que contiene capas de caliza masiva.

\section{DOMO DACÍTICO - MOORE}

La mineralización de oro en el yacimiento de Moore se encuentra localizada a lo largo del margen norte y oeste de un domo dacítico porfirítico. Este domo fue interpretado previamente (Figs. 3 y 4) como roca piroclástica. Kesler et al. (1981) cartografiaron esta unidad como un aglomerado porfirítico de cuarzo. Muntean et al. (1990) y Russell \& Kesler (1991) describieron esta unidad como toba de lapilli. Una cartografía geológica detallada para este estudio (escala 1:2000) muestra que el contacto entre el pórfido dacítico y las limolitas carbonosas, aunque localmente es paralelo a la estratificación, es en general empinado y corta a la misma. El pórfido dacítico contiene xenolitos de limolitas carbonosas que pueden llegar a un metro de longitud. Está rodeado por una zona de metamorfismo de contacto de hasta cinco metros de espesor, la cual se 


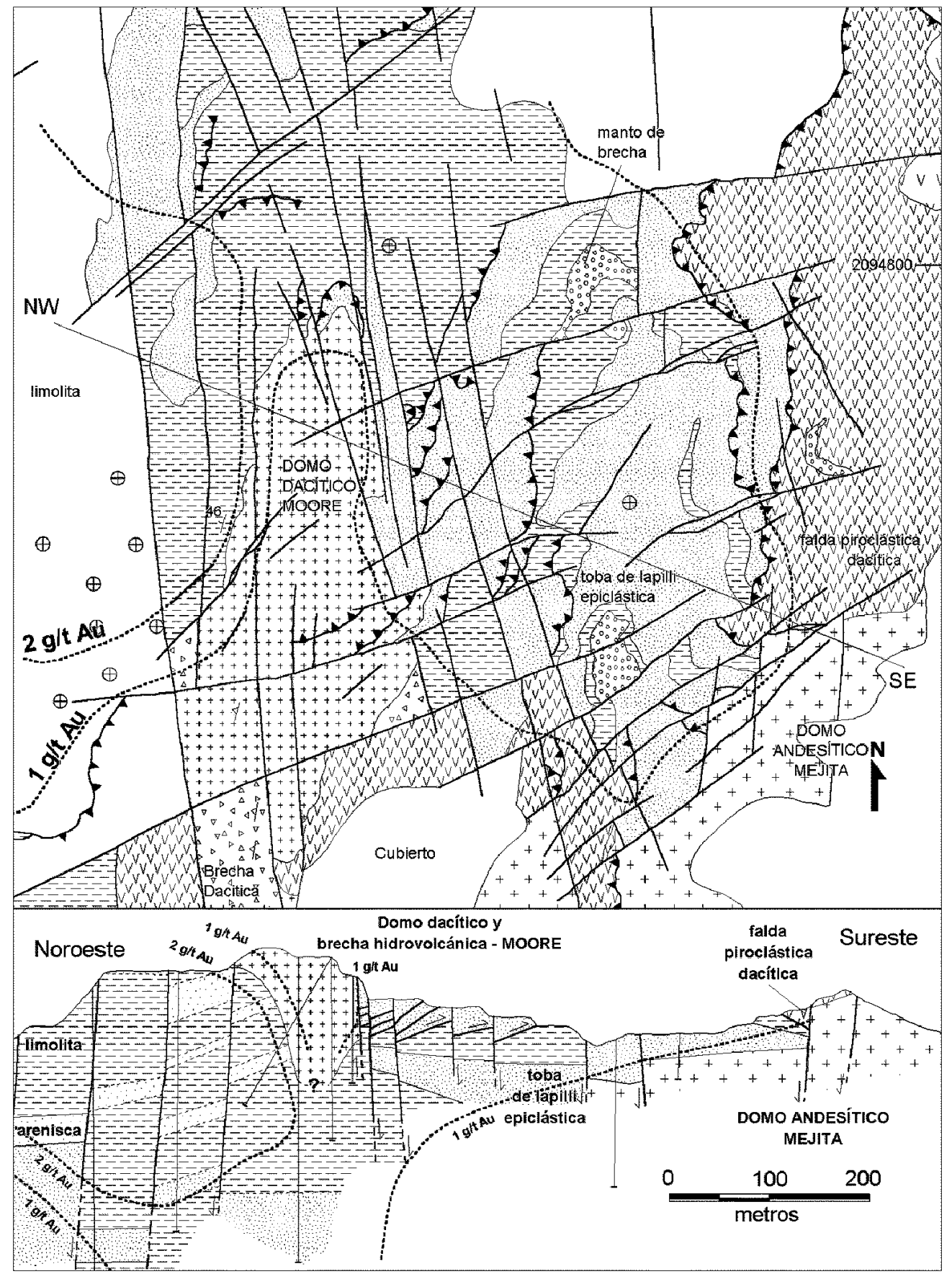

Fig. 4: Mapa geológico y sección transversal de los yacimientos de Moore y Mejita, Distrito de Pueblo Viejo, mostrando domos volcánicos en la Formación Los Ranchos. Mapa y sección están a la misma escala; no hay exageración vertical. Se han omitido las unidades que son muy delgadas para ser mostradas con claridad en la sección. Ver figura 2 para una descripción de las unidades. 
encuentra bien expuesta en el margen oeste del domo. En la zona de contacto, la estratificación está ocultada porque las limolitas exhiben un endurecimiento, de apariencia marrón claro, que es fácilmente confundible con la dacita. La presencia de contactos que cortan la estratigrafía, la aureola metamórfica y los xenolitos indican que el pórfido es de origen intrusivo, en vez de piroclástico.

Fallas inversas empinadas con unos pocos metros de desplazamiento buzan hacia el pórfido dacítico y localmente desplazan el contacto con los sedimentos circundantes. Estas fallas inversas se envuelven alrededor del margen norte del domo donde las limolitas carbonosas adyacentes, normalmente horizontales, se hallan fuertemente inclinadas. La inclinación de la sección sedimentaria fue una respuesta a la intrusión del pórfido dacítico.

La dacita es un pórfido masivo y homogéneo que contiene ojos de cuarzo distintivos. Muchos de los ojos de cuarzo exhiben contorno bipiramidal y bordes definidos, indicando que son fenocristales. En los testigos de perforación se observan mejor fenocristales grandes de feldespato potásico de hasta un $\mathrm{cm}$. El pórfido dacítico muestra texturas derivadas de esferulitas desvitrificadas, típicas de una cristalización poco profunda.

El borde del pórfido dacítico es una brecha no clasificada que contiene fragmentos alterados hidrotermalmente y abundantes ojos de cuarzo. Esta unidad se encuentra expuesta alrededor de los márgenes norte y oeste del domo (Fig. 4) y es interpretada como brecha hidrovolcánica. A unos 300 metros al este del domo de pórfido dacítico de Moore afloran rocas piroclásticas, que consisten en brechas de tobas de lapilli líticas estratificadas, de la misma composición del pórfido; el afloramiento puede trazarse hacia el Este, fuera del área del mapa (Figs. 3 y 4). El pórfido dacítico, su correspondiente brecha hidrovolcánica y el abanico piroclástico contienen todos ojos de cuarzo.

Además de los ojos de cuarzo, la brecha hidrovolcánica y las rocas piroclásticas del pórfido dacítico contienen abundantes fragmentos subangulares y subredondeados de brecha lítica andesítica, toba de lapilli y de rocas sedimentarias carbonosas. Muchos de los fragmentos se en- cuentran alterados hidrotermalmente. La matriz consiste de una harina tobácea alterada hidrotermalmente. La actividad hidrotermal continuaba cuando la erupción hidrovolcánica, impulsada presumiblemente por la intrusión dacítica, depositó las rocas piroclásticas.

Kesler et al. (1981) reportan que el contacto del pórfido dacítico con los sedimentos subyacentes es horizontal. Sin embargo, perforaciones inclinadas realizadas en 1997 revelan un contacto en forma de embudo, por lo menos a lo largo del margen norte del domo (Fig. 4). Aunque la raíz más profunda del domo no ha sido establecida, las observaciones superficiales y los resultados de las perforaciones indican que el pórfido dacítico de Moore y la brecha marginal intruyen las secciones de rocas de sedimentos carbonosos.

Las rocas sedimentarias carbonosas epiclásticas contienen flujo de escombros lenticulares de pórfido dacítico cerca del contacto con el domo volcánico. Los ojos de cuarzo detrítico son constituyentes abundantes de las rocas sedimentarias carbonosas, hasta 200 metros del margen del domo. Estas observaciones indican que las fases tempranas del pórfido dacítico fueron expuestas a la erosión durante la deposición de esta unidad.

\section{DOMOS ANDESÍTICOS - MONTE NEGRO}

El yacimiento de Monte Negro está asociado a tres domos volcánicos de composición andesítica. Estos domos fueron cartografiados previamente como espilita de Platanal (Kesler et al. 1981) y se les asignó una posición estratigráfica por debajo de los sedimentos epiclásticos carbonosos del Miembro Pueblo Viejo. La cartografía geológica y las perforaciones sugieren que las rocas volcánicas del yacimiento de Monte Negro son domos andesíticos y que los domos se hallan rodeados e interestratificados con rocas sedimentarias epiclásticas.

Evidencias de un domo volcánico en el extremo norte de Monte Negro son el bandeamiento vertical de flujo en la andesita, una textura porfirítica de abundantes feldespatos (Fig. 5A) y la presencia de depósitos de mantos de brecha fragmentaria desmoronada (descritas más abajo). 

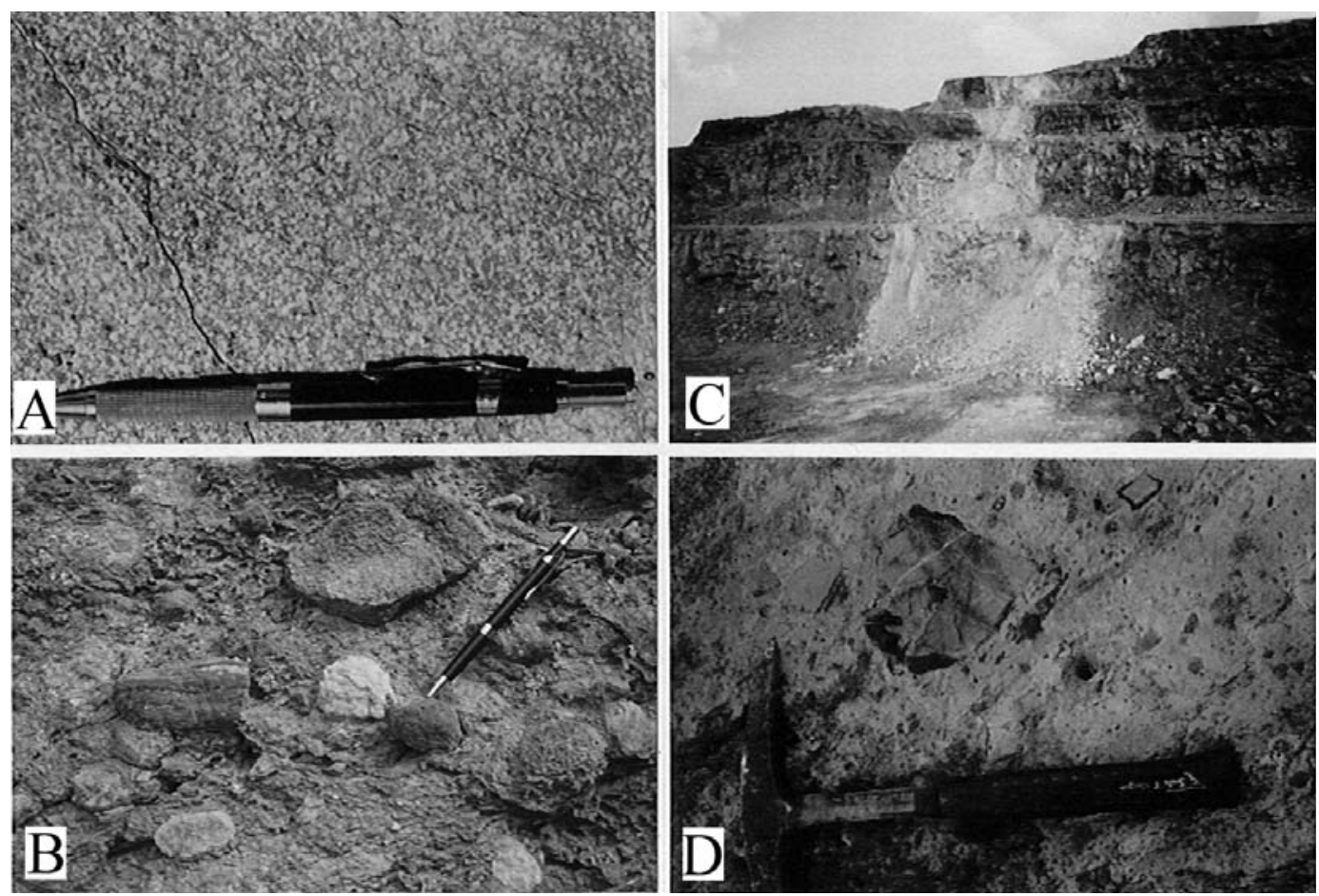

Fig. 5: Rocas volcánicas de la formación Los Ranchos. A: Pórfido de feldespato procedente de un domo andesítico en el yacimiento de Monte Negro. B: Brecha desmoronada epiclástica andesítica de Monte Negro. C: Dique andesítico cortando rocas sedimentarias carbonosas en el depósito de Monte Negro. D: Dacita y brecha de venero del yacimiento de Moore.

Los contactos intrusivos, que reflejan episodios de pulsos intrusivos dentro del domo, se encuentran bien expuestos en los testigos de perforación. Las texturas de enfriamiento rápido, observadas en testigos y afloramiento, indican que el emplazamiento ocurrió en un ambiente subacuático.

Existen dos domos andesíticos, en su mayoría enterrados, en el depósito de Monte Negro. Evidencias de estos domos son observados en testigos de perforación expuestos en secciones del manto de brecha desmoronada (Fig. 6). Los testigos de las perforaciones realizadas en 1997 , revelan abundantes contactos cortando la estratigrafía. Un sondeo profundo penetró las andesitas y volvió a entrar en los sedimentos epiclásticos carbonosos a profundidad. Ambos domos son cubiertos por la brecha fragmentaria desmoronada. Esta brecha (Fig. 5B) puede llegar a un espesor de 50 metros en los testigos. Pero, en distancias horizontales, no se extiende más de 100 metros entre los sedimentos adyacentes (Fig. 6). Esta unidad rocosa fue descrita por Kesler et al. (1981, 1991) como conglomerado espilítico. La brecha desmoronada es pobremente clasificada, soportada por matriz y compuesta principalmente por fragmentos de los domos andesíticos adyacentes. Algunos fragmentos distorsionan los estratos subyacentes indicando un origen balístico. Otros fragmentos muestran silicificación, indicando que la alteración hidrotermal continuaba durante el emplazamiento de la brecha desmoronada. Estas observaciones sugieren que las rocas volcánicas fragmentarias gruesas del tajo de Monte Negro son derivadas localmente y por lo menos en parte de una fuente piroclástica. El término brecha desmoronada sirve para enfatizar su conexión espacial y genética con los domos volcánicos adyacentes. 


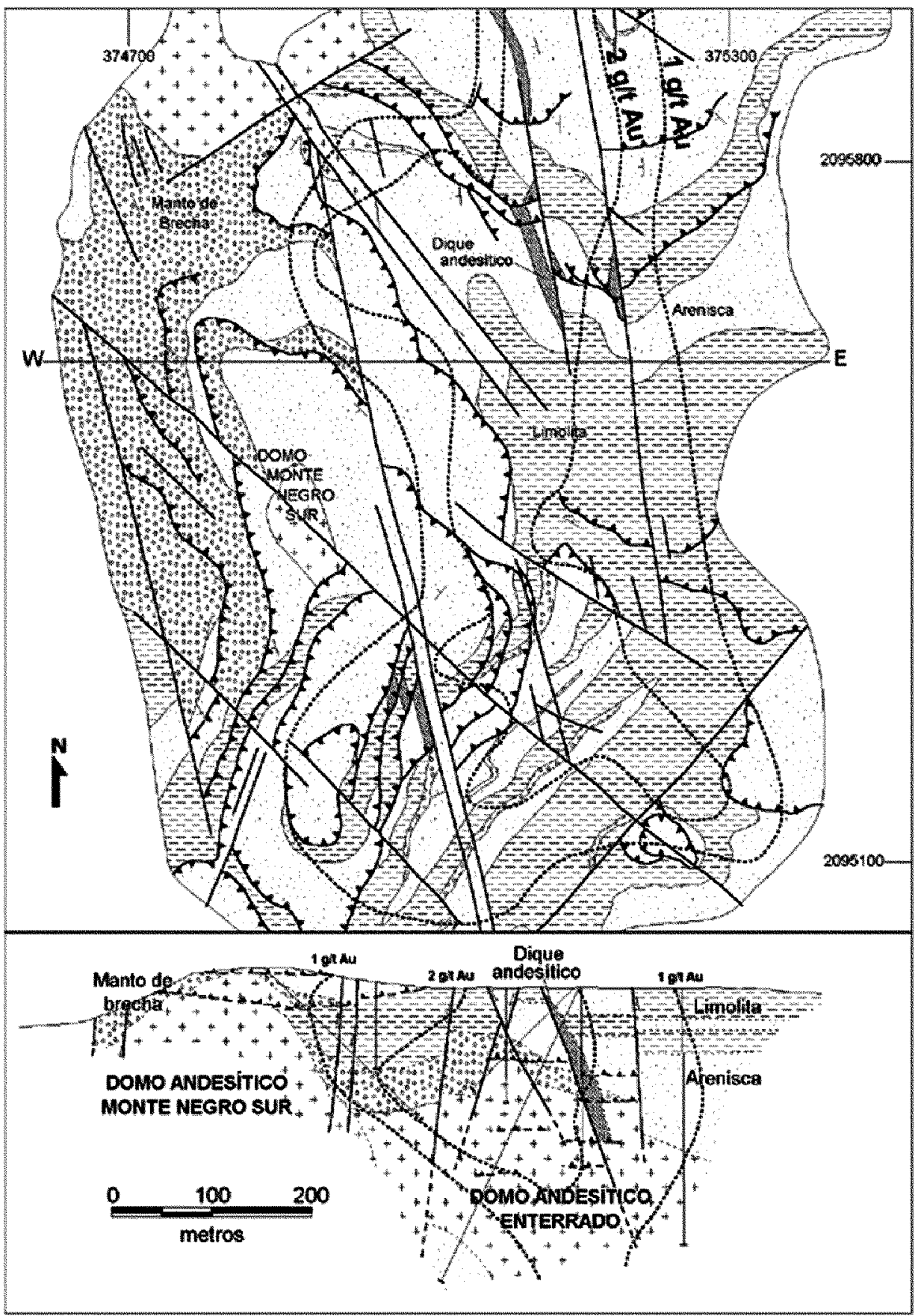

Fig. 6: Mapa geológico y sección transversal del depósito de Monte Negro, Distrito de Pueblo Viejo, mostrando domos volcánicos y sedimentos epiclásticos circundantes. Mapa y sección tienen la misma escala; no hay exageración vertical. Las unidades que son demasiado delgadas para ser mostradas con claridad en la sección han sido omitidas. Los estratos son horizontales o buzan gentilmente $\left(\operatorname{menos}\right.$ de $15^{\circ}$ ). Ver figura 2 para la descripción de las unidades. 


\section{DIQUES DE ANDESITA}

En el depósito de Monte Negro, los sedimentos carbonosos y las andesitas son intruidos por diques andesíticos casi verticales (Fig. 5C). Kesler et al. $(1981,1991)$ cartografiaron estos diques como dioritas Terciarias. Sin embargo, estudios de láminas delgadas muestran que estos diques son composicional y texturalmente idénticos a los domos andesíticos del Cretácico Temprano (Honea, com. escrita 1997) y, lo más importante, que estos diques están alterados hidrotermalmente. Sus minerales secundarios incluyen cuarzo, pirita, sericita y abundantes clastos mineralizados. Ademas, clastos mineralizados en ambas secciones, volcánica y sedimentaria epiclástica, indican que la alteración hidrotermal y la mineralización de oro fueron eventos del Cretácico Temprano coexistentes con el emplazamiento de los domos y la sedimentación. Finalmente, los dique andesíticos de Monte Negro están desplazados por fallas de cabalgamiento de bajo ángulo (Fig. 6). Las fallas de cabalgamiento, en Pueblo Viejo, son del Cretácico Medio (Draper et al., 1996).

Feldespato y sericita de un dique andesítico de Monte Negro, alterado hidrotermalmente, arrojaron una edad de potasio-argón de 46,1 +/1,2 Ma y de 63,1 +/- 1,7 Ma, respectivamente (Reesman, com. escrita 1997). Estas edades son mucho más jóvenes que la edad de la Formación Los Ranchos, del Cretácico Temprano, inferida de evidencias de fósiles (Smiley, informe interno 1982) e isótopos de plomo (Kesler et al., 1991). La poca edad y la diferencia de 17 Ma para dos muestras de un mismo dique, sugieren que sus fechas pudieron haber sido cambiadas por eventos posteriores. En la petrografía del dique andesítico (Honea, com. escrita 1997), el feldespato se encuentra reemplazado por dos generaciones de sericita de grano fino, además de cuarzo secundario y pirita. Los diques fueron probablemente alterados durante el Terciario, ya sea por el intrusivo de diorita, o por el metamorfismo relacionado con la reactivación de las fallas del Cretácico Medio (Draper et al., 1996).

En el tajo de Monte Negro, los diques del Cretácico Temprano se pueden distinguir de la diorita del Terciario que intruye la caliza de
Hatillo por la presencia de alteración hidrotermal. En los diques de andesita los feldespatos han sido remplazados por sericita y cuarzo y los minerales ferromagnesianos por sericita y clorita. El dique de diorita Terciaria que aflora en la zona del Banco Cinco no ha sido alterado hidrotermalmente. El feldespato del dique de diorita Terciaria del Banco Cinco dio una edad de 32,5 +/0,8 Ma (Reesman, com. escrita 1997).

\section{ROCAS SEDIMENTARIAS EPICLÁSTICAS}

El depósito de Moore se encuentra dentro de rocas sedimentarias carbonosas laminadas. Estas consisten en limos epiclásticos carbonosos, areniscas y conglomerados que se hacen más gruesos hacia su contacto con los domos andesíticos. El carbón en la roca es de origen agua dulce según Kettler et al. (1992). Sin embargo, un estudio isotópico de Kesler et al. (1981) sugiere un origen marino para el azufre. Vennemann et al. (1993) señalan que la espilitización de la Formación Los Ranchos resultó de la interacción con el agua marina. La presencia de fósiles terrestres de plantas indica que la profundidad del agua, marina o dulce, fue baja.

La composición de la secuencia sedimentaria epiclástica es similar a la composición de los domos volcánicos adyacentes. Sedimentos volcanoclásticos compuestos de granos andesíticos dominan la sección cerca de los domos de Monte Negro. Los estratos son generalmente de 5 a $50 \mathrm{~cm}$ de espesor y se hallan interestratificados con brecha fragmentaria andesítica de granos gruesos. Fuera del margen de los domos, los sedimentos arenosos vulcanoclásticos se interestratifican con limolita carbonosa. En los depósitos de Moore y Mejita, los sedimentos epiclásticos son de composición y apariencia similar al pórfido dacítico y su abanico piroclástico circundante.

Las brechas tobáceas del yacimiento de Mejita (Fig. 7) son interpretadas como epiclásticas, debido a que están interestratificadas con capas carbonosas y exhiben rasgos de deformación de sedimentos blandos. Las brechas epiclásticas gradúan lateralmente, a medida que se alejan del 

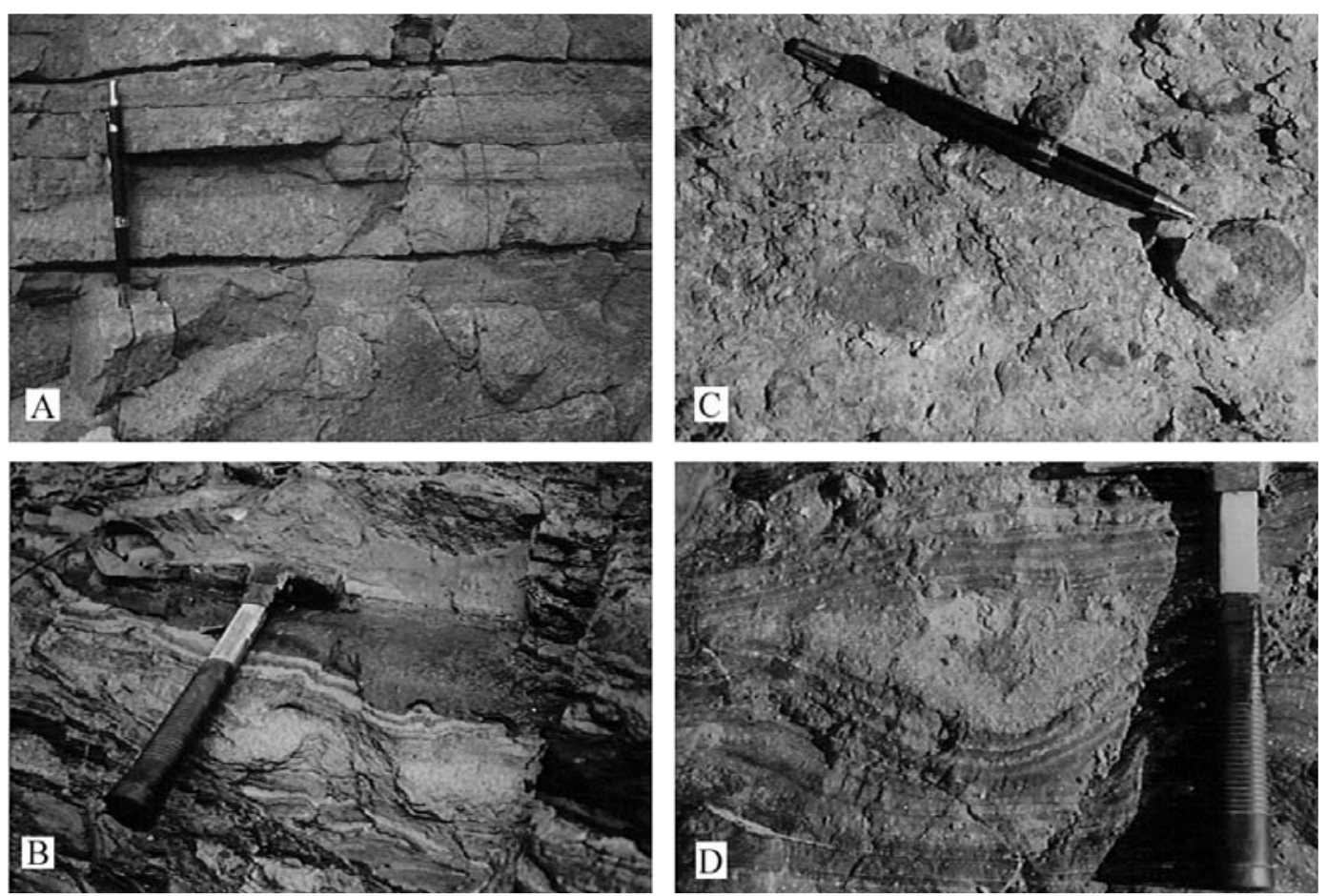

Fig. 7: Rocas sedimentarias epiclásticas de la Formación Los Ranchos. A: Arenisca carbonosa epiclástica de grano medio estratificada del depósito de Monte Negro. B: Limolita carbonosa epiclástica, finamente estratificada del depósito de Moore. C: Brecha tobácea lapilli lítica del yacimiento de Mejita. D: Impacto balístico y bolsa de bomba del yacimiento de Monte Negro.

margen del domo, a areniscas carbonosas. Entre los rasgos de deformación de sedimentos blandos se encuentran pliegues de derrumbes y diapiras sedimentarias (como resultado de desagüe).

Las rocas sedimentarias laminadas no son exclusivas del Distrito de Pueblo Viejo. Una sección epiclástica carbonosa, dentro de la Formación Los Ranchos, se expone en un prospecto adyacente a Loma Guaymarote, próximo a Bayaguana (Fig. 1). Sedimentos carbonosos también se han encontrado en la Formación Maimón, que es casi contemporánea a la Formación Los Ranchos. La Formación Maimón ha sido cartografiada tradicionalmente como una formación separada, basado en parte, en el mayor grado de metamorfismo. Sin embargo, Draper et al. (1996) argumentan que el metamorfismo se relaciona con fallas de cabalgamiento. La Formación Maimón podría ser interpretada como el equivalente me- tamórfico de la Formación Los Ranchos. Kesler et al. (1977) argumentaron en favor de correlacionar estas unidades sobre la base de similitudes texturales y composicionales y basado en sus similitudes en edad y posición estructural.

\section{FALLAS DE CABALGAMIENTO Y METAMORFISMO}

Las fallas de cabalgamiento están bien expuestas en el Distrito de Pueblo Viejo (Fig. 2). Estas buzan suavemente hacia el sudeste y el sudoeste, muestran desplazamientos pequeños hasta unas pocas decenas de metros y están marcadas por una zona con jaboncillo de arcilla y fragmentos de rocas molidas (Figs. 8A, 8B). Los pliegues relacionados con fallas de cabalgamiento en la placa superior son comunes y están bien 

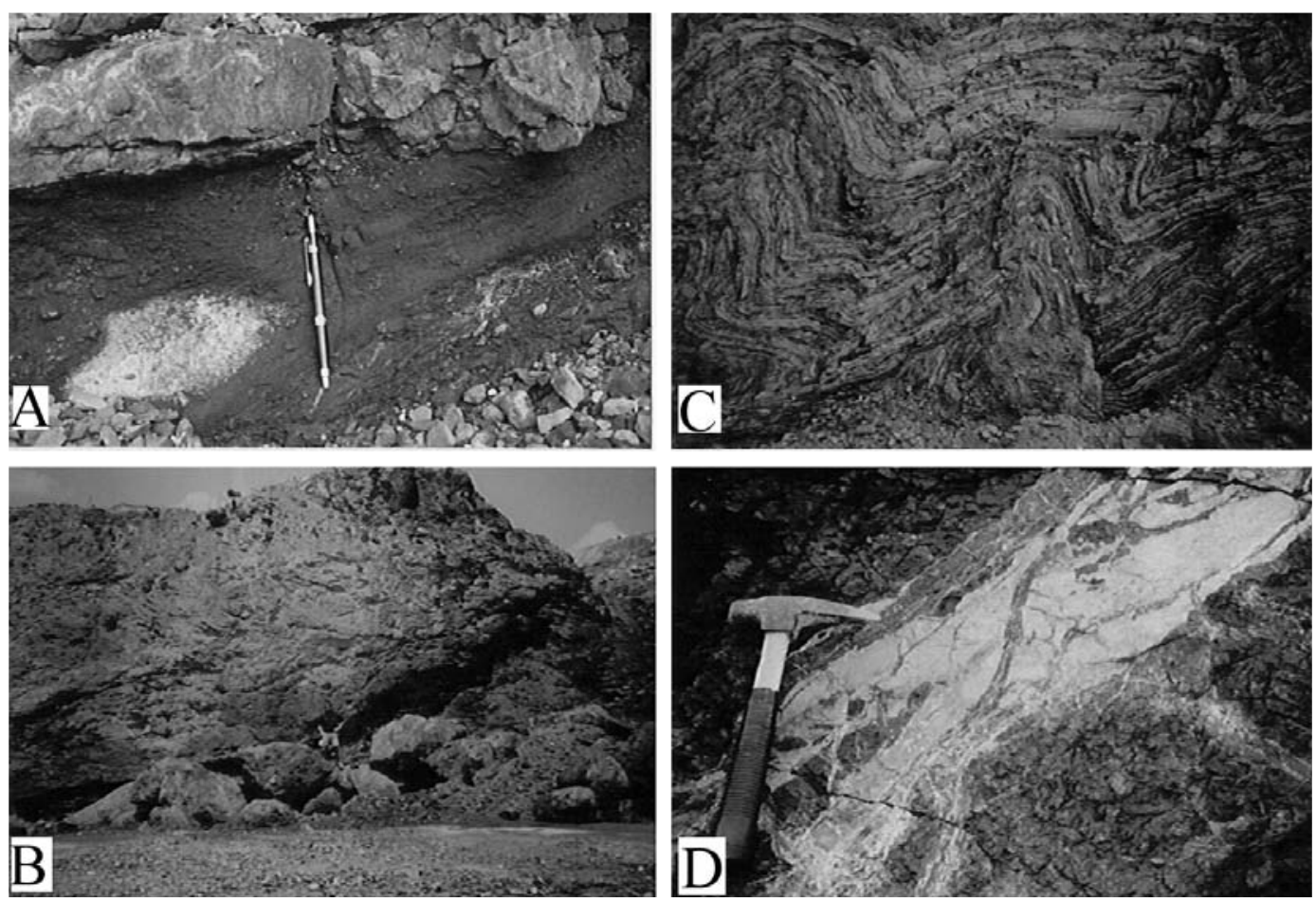

Fig. 8: Estructura del Distrito Pueblo Viejo. A: Vista cercana de una falla de cabalgamiento del yacimiento de Monte Negro. B: Vista del afloramiento de una falla de cabalgamiento en el depósito de Monte Negro. C: Pliegues en sedimentos carbonosos finamente estratificados sobre una falla de cabalgamiento en el yacimiento de Monte Negro. D: Veta de sulfuro y cuarzo con oro cortando sedimentos carbonosos, finamente estratificados, en el depósito de Moore.

mostrados en las limolitas carbonosas (Fig. 8C). Las unidades rocosas del extremo norte de Monte Negro se encuentran desplazadas de sudeste a noroeste y las del extremo sur lo están de sudoeste a noreste. Estos cambios de dirección de desplazamiento sugieren que los domos volcánicos formaron bolsones competentes alrededor de los cuales se deformaron las rocas sedimentarias locales.

El contacto de la Formación Los Ranchos con la caliza de Hatillo que lo cubre, está marcado por jaboncillo arcilloso foliado verticalmente, conteniendo fragmentos alterados hidrotermalmente (silicificado). La caliza Hatillo está brechada y cementada por calcita. Russell \& Kesler (1991) lo cartografiaron como una discontinuidad, basado, en parte, en la presencia de estratos de conglomerado en la caliza. Más recientemente, tres sondeos perforados en la Caliza Hatillo (Anon, 1998) muestran que el contacto con las limolitas carbonosas del Miembro Pueblo Viejo es una falla que buza suavemente (menos de $5^{\circ}$ ) hacia el suroeste. En la base de la caliza de Hatillo se encuentran diques dioríticos del Terciario desplazados, aportando más evidencias para la falla de cabalgamiento (Fig. 3). Aunque la evidencia presentada aquí apoya una falla de cabalgamiento en la base de la caliza Hatillo, ésta no es incompatible con la discontinuidad reportada por Russell \& Kesler (1991). Ambas interpretaciones pueden estar correctas.

Fallas de cabalgamiento de rumbo noroeste aparecen en el Distrito de Pueblo Viejo y continúan una encima de otra por una distancia indeterminada hacia noreste. Cerca del prospecto de metales preciosos de Managuá se puede observar una discontinuidad fallada, entre la Formación Los Ranchos y la Caliza de Hatillo (Fig. 1). 
Draper et al. (1996) propusieron que el fallamiento de cabalgamiento regional fue el resultado de la obducción de la corteza oceánica del Cretácico Medio. Un arco con frente hacia el suroeste, del Cretácico Temprano, cambió o fue reemplazado por uno con frente hacia el noroeste en un proceso referido como polaridad reversa. Si la caliza fallada de Hatillo desplaza diques del Oligoceno Temprano, entonces algunos de los movimientos a lo largo de la falla de cabalgamiento de Hatillo deben de ser post Oligoceno Temprano. Draper et al. (1996) sugirió que el desplazamiento de unidades más jóvenes (la Formación de Loma Caballero) indica una reactivación terciaria de las fallas de cabalgamiento del Cretácico Medio. Los desplazamientos de diques del Oligoceno Temprano del Distrito Pueblo Viejo, apoyan la reactivación de las fallas de cabalgamiento del Oligoceno Temprano.

Draper et al. (1996) también propusieron que la deformación penetrativa y la recristalización metamórfica relacionada, de la faja de Maimón y la Formación Los Ranchos fueron el resultado de la obducción de la corteza oceánica del Cretácico Medio. La recristalización metamórfica de los sedimentos carbonosos de Pueblo Viejo aumenta en intensidad de noreste a sudoeste a través del distrito. No hay evidencia de recristalización metamórfica en los extremos norte y este de los depósitos de Moore o de Monte Negro. Sin embargo, en los extremos sur y oeste de ambos depósitos las arcillas hidrotermales son convertidas en muscovita de grano muy fino, desarrollando una foliación penetrativa. Los afloramientos cercanos a la falla de cabalgamiento de Hatillo contienen hojuelas de mica muscovítica que son visibles a simple vista y exhiben una foliación metamórfica bien desarrollada. La foliación penetra y desplaza vetas de cuarzo hidrotermal en el Distrito de Pueblo Viejo, indicando que el metamorfismo postdata la mineralización de oro.

\section{MODELOS}

Una variedad de modelos genéticos ha sido propuesta para el Distrito de Pueblo Viejo. Estos modelos reflejan un entendimiento evolutivo de los yacimientos epitermales y no son tan contradictorias como podría aparentar. Kesler et al. (1981) describieron a Pueblo Viejo como un yacimiento de oro-cuarzo-pirofilita formado en un ambiente de aguas térmales. El modelo de aguas térmales está apoyado por una capa silícea (minada) y una alteración en forma de embudo, similar a las encontradas en sistemas geotérmicos activos. Muntean et al. (1990), Russell \& Kesler (1991), Kettler et al. (1992) y Vennemann et al. (1993) se refieren a Pueblo Viejo como un depósito epitermal del tipo sulfato ácido. Esta asignación está apoyada por la presencia de enargita, abundante pirofilita, diáspora localizada y alunita. Sillitoe et al. (1996) prefieren el término sulfuración intensa (en vez de sulfato ácido) y continúan describiendo a Pueblo Viejo como un yacimiento vulcanogenético de sulfuro masivo subacuoso de poca profundidad. Un origen de tipo sulfuro masivo está apoyado por la presencia de estratos con más de $75 \%$ de pirita y evidencias de un ambiente subacuático.

Este ensayo añade a la lista de modelos la propuesta de que la mineralización de oro ocurrió en un campo de domos. La cartografía geológica revela la existencia de una serie de domos volcánicos rodeados e interestratificados con sedimentos epiclásticos. La mayoría de los domos son de composición andesítica pero uno es un pórfido dacítico (Figs. 3 y 4). Algunos de los domos están flanqueados por abanicos piroclásticos (ej. Moore) mientras que otros se encuentran enterrados bajo sedimentos epiclásticos (ej. Monte Negro). Algunos de los domos son intrusivos (ej. Moore). Cada centro volcánico desarrolló su propia estratigrafía volcánica distintiva que solapa y se interdigita con rocas sedimentarias epiclásticas derivadas de los centros volcánicos adyacentes.

El ambiente geológico descrito aquí (Fig. 9A) difiere del origen de cráter de maar (Fig. 9B) propuesto por Sillitoe \& Bonham (1984) y adoptado por Russell \& Kesler (1991). En vez de un cráter de maar, la cartografía geológica revela una serie de por lo menos siete centros volcánicos separados, rellenos por domos volcánicos y rodeados por una cubierta piroclástica. Los domos andesíticos y depósitos de mantos de brecha desmoronada se encuentran interestratificados 

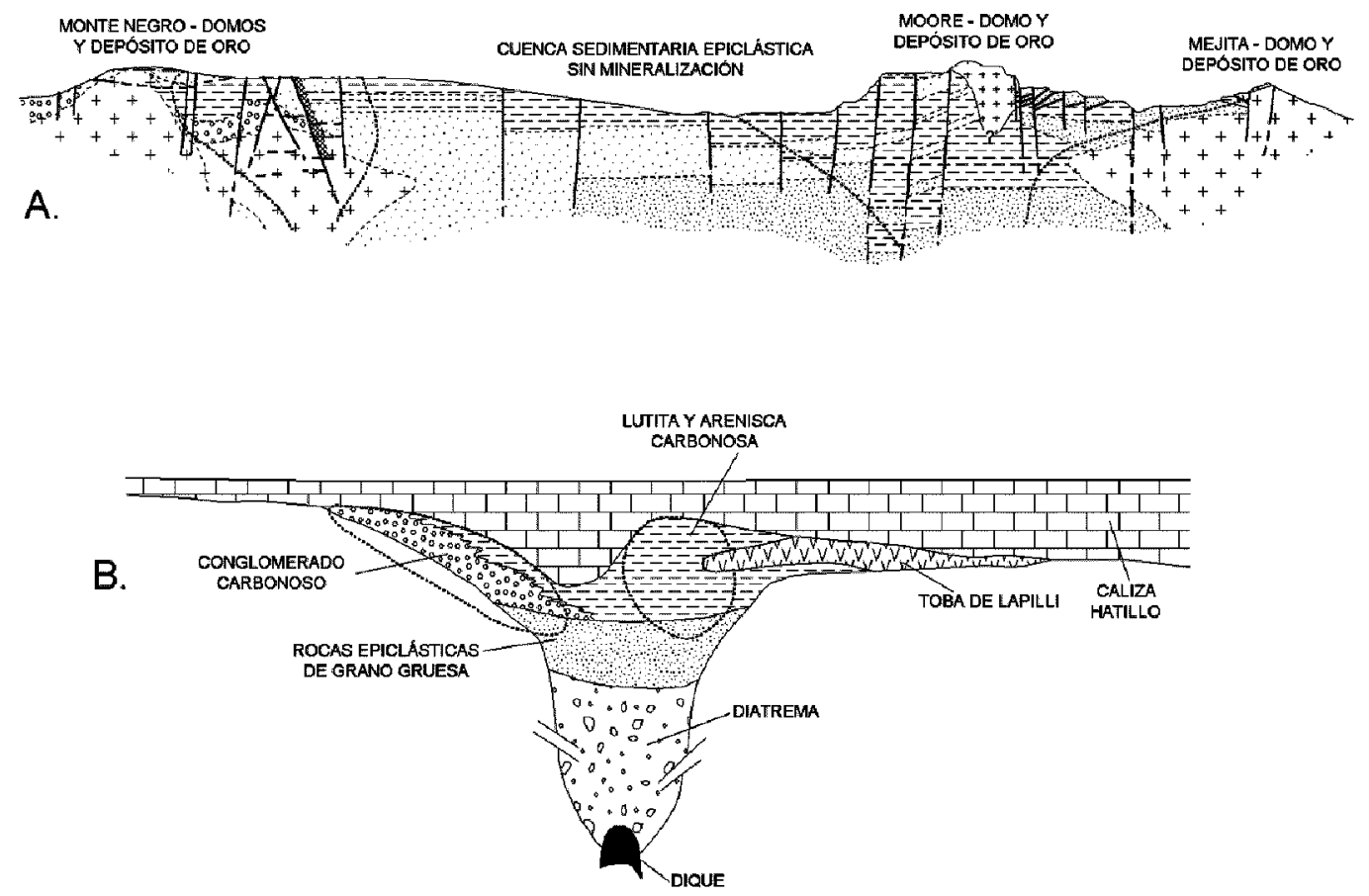

Fig. 9: Contraste entre los modelos del Distrito de Pueblo Viejo. A: Corte transversal mostrando domos volcánicos (de este artículo). B: Modelo esquemático del maar diatrema de Russell \& Kesler (1991, Fig. 5C). Las unidades sedimentarias epiclásticas aparecen en ambas secciones y se muestran con un mismo patrón. Las rocas volcánicas, mostradas como domos en la sección A, forman las paredes del maar-diatrema de la sección B. La toba de lapilli (Sección B) es reemplazada por el domo de Moore (Sección A). La caliza de Hatillo ha sido erosionada en todos sus márgenes, excepto en el sur del Distrito de Pueblo Viejo. Los yacimientos se muestran con líneas discontinuas gruesas y están centrados en los domos volcánicos de la sección A, pero siguen el margen del maar diatrema en la sección B.

con sedimentos epiclásticos carbonosos. Este cambio en la interpretación sugiere que los esfuerzos de exploración en la Formación los Ranchos deben ser enfocados en los campos de domos volcánicos. Los nuevos descubrimientos podrían o no incluir una componente epiclástica sedimentaria.

\section{CONCLUSIONES}

La cartografía geológica del Distrito de Pueblo Viejo sugiere que la mineralización de oro fue un evento del Cretácico Temprano, contemporáneo con el emplazamiento de domos volcánicos. El campo de domos se formó en los flancos del edificio volcánico de Loma La Cuaba en un arco intraoceánico emergente de tipo arco de isla. Los domos andesíticos del yacimiento de Monte Negro se encuentran cubiertos por brechas desmoronadas con fragmentos gruesos y se encuentran, en su mayoría, enterrados por rocas sedimentarias carbonosas epiclásticas. En el yacimiento de Moore, un domo dacítico y brecha hidrovolcánica intruyen la sección de sedimentos epiclásticos que lo rodean. Este ambiente geológico es inconsistente con el basamento de maar. Mas bien, los domos y los abanicos piroclásticos forman una serie de centros volcánicos separados. Estos centros volcánicos, cada uno rodeado por un paquete sedimentario epiclástico distintivo, se solapan, interdigitan y se interestratifican unos a otros.

La actividad hidrovolcánica, emplazamiento de domos, sedimentación epiclástica, 
alteración hidrotermal y mineralización de oro coinciden en tiempo y lugar. La desgasificación de los domos en ambiente subacuático, aportó probablemente una porción de los sulfuros. El oro y los metales asociados pudieron haber sido derivados por la condensación de gas volcánico, proveniente de la lixiviación hidrotermal de la porción vítrica de la pila volcánica acumulada, o por ambos.

Los domos volcánicos del Distrito de Pueblo Viejo son muy pequeños para mover las celdas hidrotermales responsables de la mineralización del oro. Se debe inferir una cámara magmática a profundidad, para alimentar estos domos y para mover una serie de celdas hidrotermales que alteraron un área de más de 40 kilómetros cuadrados. Sin embargo, no hay evidencias ni necesidad de inferir un depósito de pórfido de cobre subyacente.

La composición de los domos volcánicos de Pueblo Viejo no parece haber afectado la mineralización. La mena de oro está asociada espacialmente con domos andesíticos en el yacimiento de Monte Negro y con pórfido dacítico en el de Moore. Fuera del área de la mina los domos volcánicos muestran la misma variabilidad química.

Todas las unidades rocosas del Distrito de Pueblo Viejo están cortadas por fallas de cabalgamiento de bajo ángulo. Sin embargo, la mineralización se relaciona con alimentadores hidrotermales transversales de ángulo empinado. Las fallas de cabalgamiento comenzaron en el Cretácico Temprano a Medio, debido a la compresión, relacionada con la obducción de la litosfera, que impuso una fábrica metamórfica de bajo grado en la Formación Los Ranchos. El grado de metamorfismo aumenta y el fallamiento de cabalgamiento se hace más pronunciado, a través del Distrito de Pueblo Viejo, hacia la falla de Hatillo. Las fallas de cabalgamiento muestran evidencias de reactivación post-Oligoceno.

\section{AGRADECIMIENTOS}

El muestreo comenzó en el 1987 con el patrocinio del Fulbright Faculty Research Fellowship. El apoyo para análisis químicos y data- ciones fue provisto por St. Mary Minerals Company, Homestake Mining Company, Freeport McMoran Gold Company, Falconbridge Dominicana, BHP Internacional Inc. y Mount Isa Mines Exploration Pty. Mount Isa Mines Exploration Pty apoyó la cartografía geológica durante 1996 y 1997 y E.M. Baker participó en la cartografía geológica durante el mes de Julio, 1996.

Steve Kesler, Norman Russell, Skip Cunningham, Antonio Arribas Jr., Richard Goldfarb y John Walsh ayudaron con la revisión del manuscrito. Aunque se agradece la asistencia de las compañías e individuos mencionados anteriormente, los errores de observación y de interpretación permanecen bajo la responsabilidad de los autores.

\section{REFERENCIAS}

ANON, 1998: Deposito de caliza de transicion, Puebo Viejo, Republica Dominicana. - Programa de desarollo geológico minero (SYSMIN), 3 vols.

BOWIN, C.O., 1966: Geology of the Central Dominican Republic (a case history of part of an island arc). - En: HESS, H. H. (ed.): Caribbean Geological Investigations: Geol. Soc. Amer. Mem. 98: 11-84.

BOWIN, C.O., 1975, The geology of Hispaniola. - En: NAIRN, A.E.M. \& STEHL, F.G. (eds.): The ocean basins and margins, 3: 501-552.

CAS, R.A.F. \& WRIGHT, J.V., 1995: Volcanic successions Modern and ancient. - 528 págs. Chapman \& Hall, London.

CORBETT, G.J. \& LEACH, T.M., 1998: Southwest Pacific Rim Gold-Copper Systems - Structure, alteration, and mineralization. - Soc. Econ. Geol. Spec. Pub. 6: 237 págs.

DIAZ DE VILLAVILLA, L., MILIA, I. \& AGUIRRE, G., 1997: Bimodal volcanism in Central Cuba (Spanish). - En: Field workshop on geological correlation of Greater Antilles Volcanic Arc Terranes - Extended Abstracts, IGCP Project 364.

DONNELLY, T.W. \& ROGERS, J.J.W., 1981: Igneous series in island arcs: The northeastern Caribbean compared with worldwide island arc assemblages. - Bull. Volcanol. 43: 347-382.

DRAPER, G. \& LEWIS, J.F., 1989: Petrology y structural development of the Duarte complex, central Dominican 
Republic; a preliminary account and some tectonic implications. - En: Transactions, 9th Caribbean Geological Conference, Santo Domingo, 53-64.

DRAPER, G., GUTIERREZ, G. \& LEWIS, J.F., 1996: Thrust emplacement of the Hispaniola peridotite belt - Orogenic expression of the mid-Cretaceous Caribbean arc polarity reversal ? - Geology 24: 1143-1146.

KESLER, S.E., LEWIS, J.F., JONES, L.M. \& WALKER, R.L., 1977: Early island-arc intrusive activity, Cordillera Central, Dominican Republic. - Contrib. Mineral. Petrol. 65: 91-99.

KESLER, S.E., RUSSELL, N., SEAWARD, M., RIVERA, J., MCCURDY, K., CUMMING, G.L. \& SUTTER, J.F., 1981: Geology and geochemistry of sulfide mineralization underlying the Pueblo Viejo gold-silver oxide deposit, Dominican Republic. - Econ. Geol. 76: 1096-1117.

KESLER, S.E., RUSSELL, N., POLANCO, J., MCCURDY, K. \& CUMMING, G.L., 1991: Geology and geochemistry of the early Cretaceous Los Ranchos Formation, central Dominican Republic. - En: MANN, P., DRAPER, G. \& LEWIS, J.F. (eds.) Geologic and tectonic development of the North America-Caribbean plate boundary in Hispaniola. Boulder, Colorado, Geol. Soc. of Amer. Spec. Paper 262, 187-201.

KETTLER, R.M., RYE, R.O., KESLER, S.E., MEYERS, P.A., POLANCO, J. \& RUSSELL, N., 1992: Gold deposition by sulfidation of ferrous $\mathrm{Fe}$ in the lacustrine sediments of the Pueblo Viejo district (Dominican Republic). - The effect of Fe-C-S diagenesis on later hydrothermal mineralization in a maar-diatreme complex. - Chem. Geol. 99: 29-50.

MANN, P., DRAPER, G. \& LEWIS, J.F., 1991: An overview of the geologic and tectonic development of Hispaniola. - En: MANN, P., DRAPER, G., \& LEWIS, J.F. (eds.) Geologic and tectonic development of the North America-Caribbean plate boundary in Hispaniola. Boulder Colorado, Geol. Soc. of Amer. Spec. Paper 262, 1-28.
MUNTEAN, J.L., KESLER, S.E., RUSSELL, N. \& POLANCO, J., 1990: Evolution of the Monte Negro acid sulfate $\mathrm{Au}-\mathrm{Ag}$ deposit, Pueblo Viejo, Dominican Republic: important factors in grade development. - Econ. Geol. 85: 1738-1758.

RUIZ, J.A., 1997: Proceso de licitacion parcial de la Rosario Dominicana: Mineria, Medio Ambiente y Naturaleza - Posibilidades y compatibilidades. - Un seminario patrocinado por CEDEMPRESA y Russin, Vecchi, and Heredia Bonetti, Santo Domingo, 7 Marzo, 1997.

RUSSELL, N. \& KESLER, S.E., 1991: Geology of the maardiatreme complex hosting precious metal mineralization at Pueblo Viejo, Dominican Republic. - En: MANN, P., DRAPER, G. \& LEWIS, J.F. (eds.): Geologic and tectonic development of the North AmericaCaribbean plate boundary in Hispaniola: Boulder, Colorado, Geol. Soc. Amer. Spec. Paper 262, 203-215.

SILLITOE, R.H. \& BONHAM, H.F. Jr., 1984: Volcanic landforms and ore deposits - Econ. Geol. 79: 1286-1298.

SILLITOE, R.H., HANNINGTON, M.D. \& THOMPSON, J.F.H., 1996: High sulfidation deposits in the volcanogenic massive sulfide environment. - Econ. Geol. 91: 204-212.

STRECKEISEN, A., 1979: Classification y nomenclature of volcanic rocks, lamprophyres, carbonatites, and melilitic rocks: recommendations and suggestions of the IUGS Subcommission on the Systematics of Igneous Rocks. - Geology 7: 331-335.

TOLOCZYKI, M. \& RAMIREZ, I., 1991: Mapa geológico de la Republica Dominicana 1:250 000. - Min. Ind. Comer., Depart. de Mineria, Inst. Geogr., Universidad de Santo Domingo.

VENNEMANN, T.W., MUNTEAN, J.L., KESLER, S.E., O'NEIL, J.R., VALLEY, J.W. \& RUSSELL, N., 1993: Stable isotope evidence for magmatic fluids in the Pueblo Viejo epithermal acid sulfate $\mathrm{Au}-\mathrm{Ag}$ deposit, Dominican Republic. - Econ. Geol. 88: 55-71. 